\title{
PEMBELAJARAN KETERAMPILAN BERBAHASA ARAB RESEPTIF (TELAAH PERBANDINGAN PEMIKIRAN IBRAHIM ABDUL ALIM DAN JACK C. RICHARDS)
}

\author{
Kisno Umbar \\ Magister Pendidikan Bahasa Arab \\ Fakultas Ilmu Tarbiyah dan Keguruan UIN Syarif Hidayatullah Jakarta \\ kisno.u@gmail.com
}

\begin{abstract}
الملخص
في تعلم اللغة الاستقبالي يتم تضمينها في استراتيجيات تعلم اللغة المتعلقة بالاستماع ومهارات القراءة. هاتين المهارتين هما أساس الذهاب إلى مرحلة مهارة الكلام والكتابة أيضا. على الرغم من العديد من الافتراضات ، لمم تكن هذه الاستراتيجية التقديرية قادرة على حل المشاكل المتعلقة بتعلم اللغة اليوم ، ولكن مراجعة أفكار القادة الذين طوروا هذه الأفكار هي مسألة ملحة يجب القيام بها من أجل التحديث. في هذه الحالة ، اختار المؤلف شخصيتين هما إبراهيم عبد العليم وجاك سي ريتشاردز. في دراسة الكتاب ، اتفق الرقمان على أن تعلم اللغة يجب أن يكون له نمط واضح ، بدءا من النهج المستخدم ، تصميم التعلم بما في ذلك أهداف النهج ، وإجراءات التنفيذ. كما فعل ريتشاردز ، قام هذا بتنقيح الفكرة من أنتوني ثم جعل هذه الطريقة هي الأساس الرئيسي لتعلم اللغة ، ثم اتبعها النهج ، والتصميم ، وتقنيات التنفيذ. وبالمثل مع إبراهيم عبد العليم الذي شرح أسلوبه وفقا لمستوى القدرة والمعرفة من الطلاب ، لكنه لم يتبع بوضوح مؤامرة ريتشاردز ، لكنه شرح أيضا لكا لكابم غرض وأساليب التدريس في الفصول الدراسية.

الكلمات المفتاحية: تعلم اللغة الاستقبالية ، مهارات الكلام ومهارات الكتابة ، إبراهيم عبد العليم ، وجاك سي ريتشاردز
\end{abstract}




\begin{abstract}
Abtsrak
Dalam pembelajaran bahasa reseptif (تعلم اللغة الاستقبالية) termasuk dalam strategi pembelajaran bahasa yang berkaitan dengan keterampilan mendengarkan dan membaca. Dua keterampilan tersebut adalah dasar untuk menuju pada tahapan keterampilan oral (mahāratul kalām) dan juga menulis (mahāratul kitābah). Meskipun banyak anggapan, bahwasanya strategi reseptif ini belum bisa menuntaskan persoalan terkait pembelajaran bahasa zaman sekarang, namun meninjau kembali gagasan para tokoh yang pernah mengembangkan gagasan tersebut menjadi hal urgen yang perlu dilakukan untuk sebuah pembaruan. Dalam hal ini, penulis memilih dua tokoh yaitu Ibrahim Abdul Alim dan Jack C. Richards. Dalam kajian bukunya, dua tokoh tersebut sepakat dalam pembelajaran bahasa harus memiliki pola yang jelas, mulai dari pendekatan yang digunakan, desain pembelajaran termasuk juga tujuan dari pendekatan tersebut, yang bagaimana prosedur pelaksanaan. Seperti yang dilakukan Richards, ini merevisi gagasan dari Anthony kemudian menjadikan metode sebagai payung utama dalam pembelajaran Bahasa kemudian baru diikuti oleh pendekatan, design, dan teknik pelaksanaan. Demikian juga dengan Ibrahim Abdul Alim yang memaparkan metodenya sesuai dengan tingkatan kemampuan dan pengetahuan siswa. Namun, tidak secara explisit mengikuti alur Richards, tapi dia juga menjelaskan tujuan dan teknik pengajaran di kelas.
\end{abstract}

Kata kunci: pembelaran bahasa reseptif, mahāratul kalām dan mahāratul kitābah, Ibrahim Abdul Alim, Jack C. Richards 


\section{A. PENDAHULUAN}

Dalam pembelajaran bahasa dikenal empat keterampilan dasar, yaitu menyimak membaca, berbicara dan menulis (Yeti, tt: 1.2). Namun, jika dilihat dari strategi pengajaran bahasa, maka secara umum dapat dikelompokan menjadi dua bagian, yaitu strategi pembelajaran reseptif dan produktif. Strategi reseptif dan produktif, secara

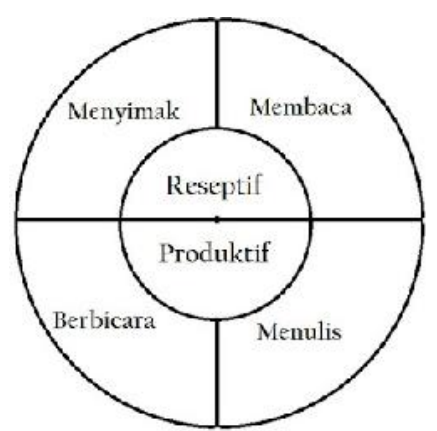

singkat bisa digambarkan pada gambar berikut ini:

Gambar 1. Diagram strategi pengajaran bahasa reseptif dan produktif (Tarigan, 2009).

Strategi reseptif pengajaran bahasa mencoba menentukan strategi pembelajaran yang akan digunakan oleh para pembelajar. Biasanya, strategi pembelajaran yang dimaksud terdiri atas proses masukan yang diam tanpa adanya produksi sesuai ucapan dalam bahasa sasaran. Seperti diagram diatas, reseptif ini terdiri dari keterampilan menyimak dan membaca. Sementara strategi produktif merupakan strategi pembelajaran yang sifatnya keluaran atau produksi. Strategi produkif ini mencakup berbicara dan tulisan.

Jika ditinjau mendalam dua strategi tidak dapat dipisahkan, bagaikan dua sisi dalam sebuah koin. Keterampilan mendengarkan itu memiliki relasi langsung dengan aktifitas lisan atau mendengarkan orang yang berbicara. Sedangkan, keterampilan 
membaca itu berkaitan langsung dengan hasil dari tulisan. Tidak mungkin bisa membaca tanpa adanya sebuah tulisan.

Pada kajian literatur ini, penulis akan fokus pada keterampilan reseptif. Alasanya, keterampilan reseptif berkaitan dengan proses pemerolehan bahasa dalam kajian psikolinguistik. Seoarang anak yang lahir ke dunia, hanya bisa melakukan aktifitas pendengaran, sebagaimana firman Allah swt. dalam QS. As-Sadjah, Ayat 9.

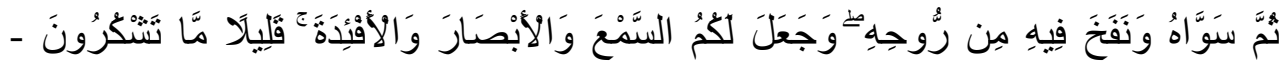
rr:q

“Kemudian Dia menyempurnakannya dan meniupkan roh (ciptaan)-Nya ke dalam (tubuh)nya dan Dia menjadikan pendengaran, penglihatan dan hati bagimu, (tetapi) sedikit sekali kamu bersyukur (Al-Quran Terjemahan Kementerian Agama edisi revisi 2016).”

Strategi pembelajaran yang seperti ini dapat juga dipandang sebagai suatu manifestasi strategi abdi-ordinat (super-ordinat) pemerolehan bahasa yang biasanya terbatas sebagai formal dan tes hipotesis. Akan tetapi, dalam hal ini tes hipotesis tidak berkaitan dengan umpan balik yang mengikuti upaya para pembelajar dalam berkomunikasi, tetapi justru didasarkan pada observasi masukan bagi konfirmasi atau nonkonfirmasi dari hipotesis para pembelajar (Tarigan, 2009).

Untuk memahami lebih detail terkait relasi dua item dalam strategi keterampilan bahasa reseptif, Nababan menggambarkan dalam diagram berikut ini (Yeti, tt: 1.22).

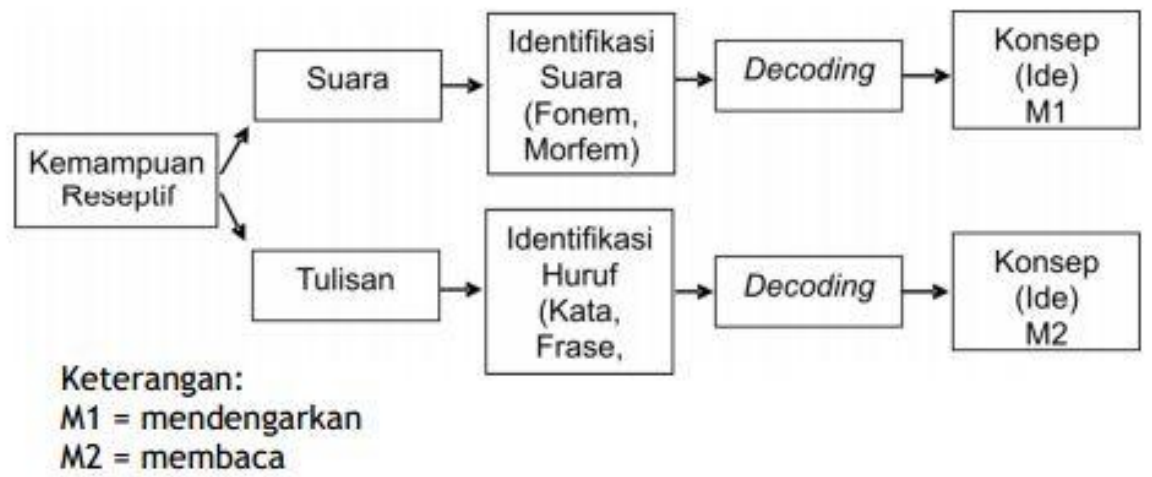

Gambar 2. Diagram mendengarkan dan membaca 
Dari diagram di atas, keterampilan mendengarkan ataupun membaca merupakan kegiatan berbahasa yang bersifat reseptif. Adapun perbedaannya terletak pada objek yang menjadi stimulus. Pendengaran fokus pada stimulus berupa suara, sementara membaca pada lambang tulisan. Namun, semuanya tetap melakukan pengidentifikasian pada unsur-unsur bahasa baik yang berupa suara (fonem, morfem) juga tulisan (kata dan frase).

Karena siginifikansi dan peran dasar dari keterampilan reseptif dalam pengajaran bahasa, penulis berusaha memformulasikan konsep pembelajaran bahasa reseptif dengan membandingkan dua pakar pembelajaran bahasa (language teaching atau) dari Abdul Alim Ibrahim dari pembelajaran bahasa Arab dan Jack C. Richards dari pakar Teaching English to Speakers of Other Languages (TESOL). Ibrahim lebih dikenal dengan karyanya almuwajjah al fany li mudarisi al-lughah al-arabiyah, dan juga an nahwu al-wadhifi, sedangkan Richards sangat dikenal dengan karyanya Approaches and Methods in Language Teaching yang sudah dicetak hingga 15 kali lebih sejak diterbitkan perdana pada tahun 1986.

Gagasan dua tokoh tersebut sebetulnya tidak hanya keterampilan bahasa reseptif saja, namun secara umum mengulas empat keterampilan dalam berbahasa. Sekali lagi, penulis ingin menegaskan, kajian ini bukan untuk mendikotomikan keterampilan berbahasa reseptif dan produktif, tetapi lebih pada penekanan aspek dasar dari pembelajaran bahasa (Adawiyah, 2016: 29). Tujuannya tentu mereview kembali pemikiran dari para tokoh untuk kemudian bisa elaborasikan dan disesuaikan dengan situasi dan kondisi dari tren keterampilan dalam pembelajaran bahasa terkini. Penulis sadar bahwasanya, untuk melahirkan formulasi baru dari keterampilan reseptif penting untuk meninjau pemikiran para pakar terdahulu. 


\section{B. Biografi Tokoh}

\section{Biografi Ibrahim Abdul Alim}

Ibrahim Abdul Alim atau Abdul Alim Ibrahim adalah seorang Dekan Inspeksi Bahasa Arab di Departemen Pendidikan. ${ }^{1}$ ia dilahirkan di Aleppo pada tahun 1933 Masehi. Ibrahim menerima ijazah bahasa Arab pada tahun 1959 Masehi, kemudian ia menerima sertifikat diploma dalam Pendidikan Inspeksi dan Statistik dari Universitas Damaskus, dan Master pada tahun 1964 Masehi dan $\mathrm{PhD}$ dalam Sastra Kuno dari Universitas Al-Azhar pada tahun 1966 Masehi.

Ibrahim Abdul Alim termasuk sosok yang memiliki sumbangsih dalam pembangunan intelektual di Fakultas Adab di Universitas Aleppo. Ia pernah dipercayai sebagai seorang guru sastra kuno dan analisis teks kitab-kitab klasik dan aset penelitian dan investigasi.

Salah satu karya Ibrhaim adalah mentahkik Tafsir Jalalain dengan penambahan i'rāb yg rinci. $^{2}$ Kemudian beberapa gagasan dan pemikiran dari Ibrahim Abdul Alim tertuang dalam beberapa karyanya seperti al-muwajah al fany li mudarrisi al-lughah al-arabiyah (الموجه الفني لمدريس اللغة العربية), an-nahwu al-wadhifi (النحو الوظيفي), al-imla wa at-tarqim fi kitabi al-Arabiyah (الإملاء و الترقيم في (كتاب العربية), Shofwatul 'arudh (صفوة العروض), taisirul I'lāl wal ibdāl ( تيسير الإعلال

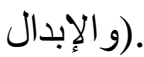

\section{Biografi Jack C. Richards}

Richards atau dikenal dengan nama Jack C. Richard lahir tahun 1943 di Selandia Baru (Richards, 2006: 43). Sekarang, usinya mencapai 75 tahun. Richards meraih gelar Master of Arts (MA) dengan penghargaan kelas satu dalam bahasa Inggris dari

\footnotetext{
1. الاملاء والترقيم فى كتابة العربية http://www.bookssd.com/2012/11/blog-post_14.html, diakses pada 3 Desember 2018.

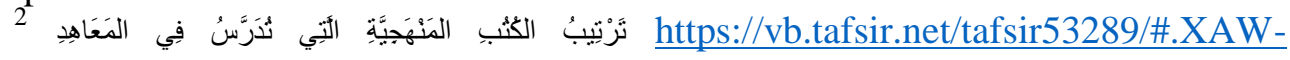
UTOIbIU, diakses pada 3 Desember 2018
} 
Universitas Victoria di Wellington, Selandia Baru, pada tahun 1966. Kemudian ia juga memperoleh gelar Ph.D. dalam bidang linguistik terapan dari Laval University ( $a$ French-Language University) in Quebec City, Canada in 1972. ${ }^{3}$

Richards termasuk intelektual modern yang getol berbagi pengetahuan di banyak bagian dunia, seperti di Kanada, Indonesia, Singapura, Hongkong, dan Amerika Serikat. Ia juga ternyata pernah mengajar di Indonesia setelah menyelesaikan studi Ph.D. Di Singapura, Prof. Richards pernah ditunjuk sebagai spesialis dalam linguistik terapan di Regional Language Centre Singapore di bawah naungan Pemerintah Selandia Baru. Sedangkan di Hongkong, ia diangkat sebagai dosen senior dalam bahasa Inggris di Chinese University of Hong Kong, sebelum diangkat menjadi profesor penuh di Departemen Bahasa Inggris sebagai bahasa Kedua di University of Hawaii pada tahun 1981. ${ }^{4}$ Rangkaian mobilitas akademik yang tinggi Richards itu menunjukkan kapasitasnya tidak hanya diakui di Selandia Baru saja, atau di Kanada, namun hampir di beberapa kampus di belahan dunia.

Richards ternyata juga pernah mendirikan jurusan bahasa inggris di beberapa universitas di dunia, seperti di City University of Hongkong. Di sana, ia juga menjabat sebagai kepala jurusan sekaligus sebagai ketua profesor. Kemudian Richard juga mendirikan program MA di Universitas Auckland, Salandia baru, tanah kelahirannya. ${ }^{5}$ Upaya dalam pengajaran bahasa Inggris Richards ternyata tidak berhenti pada aktifitas mengajar saja, ada upaya untuk mendorong beberapa universitas mendirikan jurusan (departmen) bahasa Inggris.

Pada tahun 1999, Prof. Richards pensiun dari administrasi universitas. Namun, aktifitasnya sebagai seorang lecture tidak pernah purna, sejak itu ia mengajar secara rutin di Regional Language Centre (RELC) di Singapura, ketika ia tinggal di Sydney, Australia. Di RELC, Dr. Richards mengajar di MA dalam program Linguistik Terapan,

${ }^{3}$ About Professor Richards, https://www.professorjackrichards.com/about/, diakses pada 29 November 2018.

${ }^{4}$ Dari penelusuran penulis, Prof Richards pernah mengajar di Satya Wacana University, Salatiga, Central Java, Indonesia held October 26-30 2015. https://www.professorjackrichards.com/speakingtours/indonesia/, diakses pada 30 Nov 2018.

5 About Professor Richards, https://www.professorjackrichards.com/about/, diakses pada 29 November 2018. 
serta Diploma Pasca Sarjana RELC dalam Linguistik Terapan. ${ }^{6}$ Aktifitas lainnya, seperti kegiatan mengisi kuliah umum, stadium general juga masih sangat rutin di lakukan hampir di seluruh dunia. Seiring berkembangnya era globalisasi, Prof Richard juga membangun website offisial resmi yang menjadi media komunikasi dengan publik. Website tersebut yang kemudian menjadi wadah kuliah online, serta arsip online dari publikasi jurnal dan buku dari prof Richards. Bahkan, ia juga melayani aktifitas Q \& A (tanya jawab) seputar language teaching.

Oleh sebab itu, nama Richard tidak asing lagi di kalangan linguis dunia. Hal tersebut dikarenakan gagasanya yang gemilang dalam kajian linguistik terapan (Aplied Linguistic) khususnya dalam bidang language teaching lebih spesifik pada Teaching English to Speakers of Other Languages (TESOL). ${ }^{7}$

Richards termasuk intelektual yang rajin dalam menyampaikan gagasannya lewat tulisan. Pada tahun 2018 sekarang ini saja, di usianya yang senja, ia masih menghasilkan lima publikasi, diantaranya editor in chief di RELC Journal, ${ }^{8}$ kemudian menulis Afterword (Epilog) pada buku Emotions in Second Language Teaching (Agudo, 2018, 445-449). kemudian Planning a Language Course: Principles and Procedure (Richards, 2018: 70), Product and process in second language teacher education (Richards: 2018, 270), dan The Cambridge Guide to Learning English as a Second Language. Anne Burns and Jack C Richards (editors) (Editor Richards, 2018: 350).

Di samping tulisan tersebut, secara keseluruhan sejak 1967 silam, Richards sudah menghasilkan lebih dari 150 artikel dan buku. Banyak dari buku dan artikelnya yang klasik di bidang pengajaran bahasa kedua dan telah diterjemahkan ke banyak bahasa yang berbeda, termasuk Spanyol, Cina, Korea, Jepang, dan Arab.

${ }^{6}$ About Professor Richards, https://www.professorjackrichards.com/about/, diakses pada 29 November 2018.

7 Pada tahun 2016 organisasi TESOL Internasional sebagai bagian dari ulang tahun ke-50 mereka menghormati Jack Richards sebagai salah satu dari 50 spesialis TESOL di seluruh dunia telah membuat dampak yang signifikan terhadap pengajaran bahasa dalam 50 tahun terakhir. https://www.professorjackrichards.com/about/ diakses pada 29 November 2016.

${ }^{8}$ RELC Journal, https://journals.sagepub.com/doi/abs/10.1177/0033688218785195 diakses pada 30 November 2018. 
Di antara buku-buku profesionalnya yang terkenal adalah Error Analysis, (1974), Reflective Teaching in Second Language Classrooms (1996, dengan Charles Lockhart), Beyond Training (1998), The Language Teaching Matrix (1990), Pengembangan Kurikulum dalam Pengajaran Bahasa (2001), Approaches and Methods in Language Teaching (edisi ketiga 2014, dengan Ted Rodgers), Longman Dictionary of Language Teaching and Applied Linguistics (Edisi ke-4 2010, dengan Richard Schmidt) Professional Development for Language Teachers (dengan Tom Farrell), Cambridge Guide to Second Language Teacher Education, (2009, edited with Anne Burns) Cambridge Guide to Pedagogy and Practice in Language Teaching (edited with Anne Burns), Language Learning Beyond the Classroom (Routledge 2014, edited with David Nunan,) Key Issues in Language Teaching (Cambridge 2015).

Prof Richards mendapat pengakuan luar biasa dari Presiden De La Salle University, Manila dan Philippine Normal University, Manila, atas kedermawannya dalam berbagai pengetahuan secara terbuka kepada siapapun.

Ungkapan tersebut disampaikan pada tahun 2001, sebagaimana berikut ini:

"Generous in sharing his expertise with junior members of the profession, unstinting in his efforts to promote excellent language teaching in all parts of the world, indefatigable in showing the applications of theory to teaching practice in the classroom, Dr. Richards is a fine example of what English language education and applied linguistics can accomplish. "19

Ungkapan tersebut bisa diartikan: Murah hati dalam berbagi keahliannya dengan anggota yunior dari profesi, tanpa henti dalam upayanya untuk mempromosikan pengajaran bahasa yang sangat baik di semua bagian dunia, tak kenal lelah dalam menunjukkan penerapan teori untuk mengajar praktik di kelas, Dr. Richards adalah contoh yang baik dari apa yang pendidikan bahasa Inggris dan linguistik terapan dapat capai."

Adapun anugrah yang pernah diraih oleh Richards gelar kehormatan atas kontribusi untuk pengajaran bahasa dan sastra Inggris dari Doctor of Literature oleh

${ }^{9}$ About Professor Richards, https://www.professorjackrichards.com/about/, diakses pada 29 November 2018. 
Victoria University, Wellington pada Desember 2011. University of Sydney, Australia juga pernah menganugerahkan profesor kehormatan di Fakultas Pendidikan di tahun yang sama. Sementara pada tahun 2014, gelar profesor kehormatan diberikan Fakultas Pendidikan di Universitas Auckland, Selandia Baru. Kemudian di tahun yang sama pula, ia menjadi profesor kehormatan dan menerima penghargaan bergengsi untuk Patronage oleh Yayasan Seni Selandia Baru, atas dukungannya untuk musik dan seni.

\section{Perbandingan Pemikian Tokoh}

\section{Pemikiran Ibrahim Adul Alim}

Ibrahim Abdul Alim memiliki sebuah sumbangsih yang sangat besar bagi perkembangan bahasa Arab. Ibrahim telah menulis dua kitab besar yang menyelami dunia bahasa Arab dan hingga sekarang masih sering digunakan sebagai rujukan, yaitu Almuwajjah Alfany Li Mudarrisi Al-Lughah Al-Arabiyah

(الموجة الفني لمدرسي اللغة العربيو ) dan an-nahwu al-wadifi (النحو الوظيفي). Kedua kitab ini adalah bukti bahwa beliau ikut andil dalam mengembangkan bahasa Arab.

Di dalam kitabnya الموجه الفني menuliskan tentang konsep pengajaran ilmu bahasa Arab dan tarbiyah islamiyah, di sini beliau lebih menekankan beberapa hal di antaranya (Abdul Alim, tt):

1. Buku ini lebih fokus pada aspek ilmiah dan metode pengajaran praktis;

2. persiapan pembelajaran dan kinerja;

3. beberapa contoh pelajaran di berbagai maharāt bahasa Arab;

4. salah satu fondasi penting dari pendekatan buku ini adalah pemisahan tema dalam metode pengajaran maharāt bahasa Arab dalam berbagai tahap pendidikan, setiap tahap secara terpisah, dan;

5. Buku ini tidak terbatas pada metode pengajaran di kelas tetapi melampaui bab ke bidang kegiatan linguistik kebahasaan.

Selain itu, Ibrahim dalam kitab ini juga membahas tentang beberapa keterampilan bahasa seperti القراءة، التعبير، الإملاء، القواعد النحوي yang dijelaskan 
secara terperinci. Pada qirā'ah misalnya, Ibrahim menjelaskan tentang alqirā'ah mulai dari pengertiannya, peran al-qirā'ah dalam kehidupan baik itu secara pribadi maupun dalam kehidupan bermasyarakat, bagaimana mengajarkan al qirä'ah, dan macam macam al-qirä'ah. Ibrahim juga mengkategorikan alistima $\bar{a}$ ' sebagai bagian dari macam-macam al-qirä'ah.

Sementara itu, pada kitabnya Almuwajjah Alfany Li Mudarrisi Al-Lughah Al-Arabiyah, Ibrahim juga memaparkan banyak hal mengenai konsep - konsep pendidikan hingga masuk pada tataran kurikulum dan metode pembelajaran keterampilan bahasa. Secara umum dapat kita lihat, acuan Ibrahim dalam mengembangkan kitabnya adalah pada seni. Pembelajaran menurutnya adalah sebuah seni mengajar. Dalam hal ini berarti mengajar itu tidak murni pada ilmu pendidikan, namun melibatkan juga ilmu psikologi dalam mengantarkan sebuah materi (Abdul Alim, tt: 25).

Dalam mengajarkan keterampilan berbahasa reseptif yang telah diberikan batasan di dalam pendahuluan, Ibrahim ternyata menghasilkan konsep yang sangat detail, utamanya mengenai keterampilan membaca (مهارة القراءة), sementara istimā' menjadi bagian dari qirā'ah.

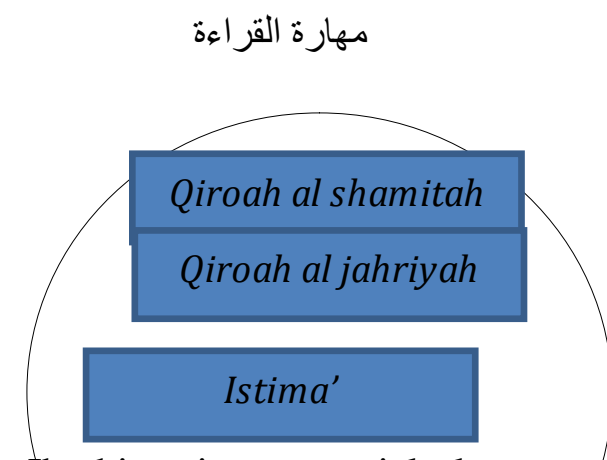

Lebih dari itu, Ibrahim juga menjelaskan metode metode dalam meningkatkan keterampilan berbahasa sesuai dengan tíngkatan peserta didik. Pada tingkatan pertama, ada beberapa metode dalam fase ibtidā'iyah, di antaranya: al thariqah al tarkibiyah, al thariqah al tahliliyah, al thariqah al 
mufadhalah fi ta'limil al qiraah lil mubtadi'in, al tahriqah al muzdawijah. Namun di antara semua metode tersebut, Ibrahim memberikan pertimbanganpertimbangan untuk menyesuaikan dengan kondisi peserta ajarnya. Misalnya, pada al thariqah at tahliliyah kebalikan dari metode tarkibiyah bisa diterapkan karena minimnya pengetahuan peserta didik dengan benda-benda dan namanya.

\section{Konsep Pengajaran Bahasa ala Richards}

Gagasan Richard terkait dengan pembelajaran bahasa lebih dikenal dari bukunya yang diterbitkan perdana pada 1986 dengan judul Approaches and Methods in Language Teaching yang ditulis secara kolaboratif dengan Theodore Rodgers. Di tahun 2014 lalu, buku tersebut sudah masuk tahapan cetak edisi ketiga oleh Cambridge University Press.

Pemikiran Richards yang tertuang dalam buku tersebut memang sangat menarik untuk ditelaah para pengakaji linguistik terapan khususnya pengajaran bahasa. Sebelum membangun gagasan pada pendekatan, metode, teknik atau istilah-istilah lain, Richards memaparkan beberapa fakta pengajaran bahasa di tahun 1980-an. Di antaranya adalah The Grammar-Translation method, language teaching innovation in the nineteenth century, Reform movement, Direct Method, The Methods era, Approaches and methods in teacher preparation programs.

Jack C. Richards dan Theodore Rodgers merevisi konsep pembelajaran bahasa yang telah dirumuskan oleh Edward Anthony. Anthony mengkonseptualisasikan bahwa dalam pembelajaran bahasa ada tiga terminologi utama yang harus dipahami, yaitu aproach, method, dan tecnique (Anthony, 1963). Aproach (pendekatan) didefinisikan sebagai seperangkat asumsi korelatif yang berhubungan dengan sifat pengajaran dan pembelajaran bahasa. Suatu pendekatan bersifat aksiomatis. Ini menggambarkan sifat materi pelajaran yang akan diajarkan (Richards \& Rodgers, 2001: 19). Artinya yang dimaksud dengan pendekatan pembelajaran bahasa dalam hal ini adalah sebuah asumsi yang mengungkapkan pengertian-pengertian dasar perihal bahasa, pembelajaran dan 
pengajaran yang kemudian dihubungkan menjadi sebuah pengertian dasar tentang Pengajaran dan Pembelajaran Bahasa.

Adapun method, menurut Anthony adalah rencana keseluruhan untuk presentasi materi bahasa secara tertib, tidak ada bagian yang bertentangan, dan semuanya didasarkan pada pendekatan yang dipilih. Suatu pendekatan bersifat aksiomatis, suatu metode bersifat prosedural (Richards \& Rodgers, 2001: 19). Artinya berdasarkan definisi di atas yang dimaksud dengan metode adalah suatu sistem perencanaan yang disusun secara sistematis dari awal sampai dengan evaluasi mengenai pelaksanaan pengajaran dan pembelajaran bahasa di dalam kelas dengan berlandaskan satu pendekatan pengajaran dan pembelajaran bahasa tertentu. Sementara itu, dalam satu pendekatan, bisa ada banyak metode.

Sedangkan yang dimaksud dengan teknik pembelajaran bahasa ialah teknik adalah implementasional-yang sebenarnya terjadi di ruang kelas. Ini adalah trik, taktik, atau penemuan tertentu yang digunakan untuk memenuhi tujuan langsung. Teknik harus konsisten dengan metode, dan karena itu selaras dengan pendekatan juga (Richards \& Rodgers, 2001: 19). Jadi teknik itu suatu aktivitas yang secara khusus dan nyata yang dimanifestasikan dalam suatu pola pembelajaran bahasa di dalam kelas sesuai dengan metode yang digunakan juga sejalan dengan pendekatan pembelajaran dan pengajaran bahasa tertentu.

Richards melihat approach dan method diperlakukan seperti design yang berkaitan dengan tujuan, silabus. Pada tahap ini juga pengajar, pelajar dan instruktur lebih dispesifikkan. Oleh sebab itu, Jack Richards dan Theodore Rodgers memodifikasi teori yang diungkapkan oleh Edward Anthony. Istilah-istilah seperti pendekatan (approach), metode (method), dan teknik (technique) diubah secara berurutan menjadi pendekatan, desain, dan prosedur (Richards \& Rodgers, 2001: 20). Sementara, menurut Richards dan Rodgers metode merupakan payung teori yang spesifik dan hubungannya antara teori dan praktik. Pendekatan didefinisikan sebagai asumsi, kepercayaan mengenai teori dasar bahasa dan pengajaran bahasa. Desain lebih khusus lagi adalah hubungan antara teori pengajaran di dalam kelas terkait materi dan aktivitas. Adapun 
prosedur didefinisikan sebagai teknik dan latihan yang mendukung penerapan dari pendekatan dan desain.

Untuk dapat memahami term yang digunakan richard, perhatikan tabel berikut ini (Richards \& Rodgers, 2001: 32):

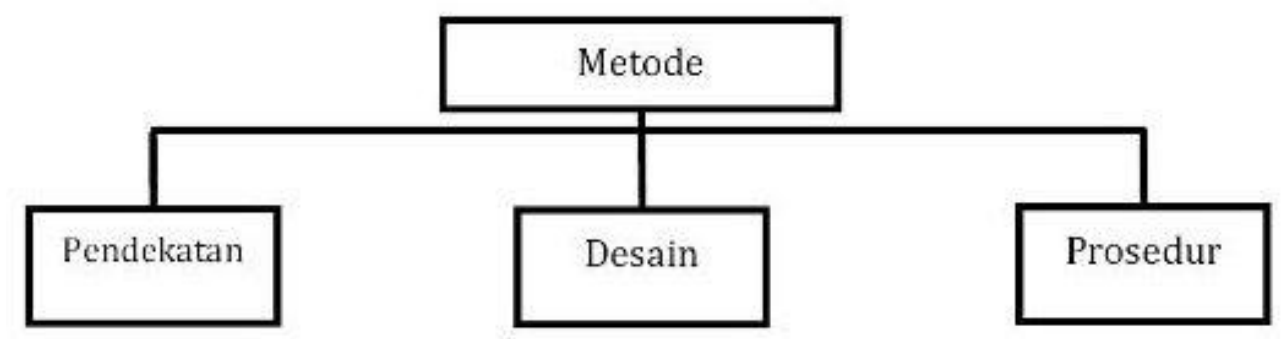

\begin{tabular}{|c|c|c|}
\hline $\begin{array}{l}\text { a. Teori hakikat bahasa } \\
\text { - Catatan hakikat } \\
\text { kemampuan } \\
\text { berbahasa } \\
\text { - Catatan unit-unit } \\
\text { dasar bahasa } \\
\text { b. Teori hakikat } \\
\text { pembelajaran } \\
\text { - Catatan proses- } \\
\text { proses } \\
\text { psikolinguistik dan } \\
\text { kognitif yang terl } \\
\text { - ibat dalam } \\
\text { pembelajaran } \\
\text { bahasa } \\
\text { - Catatan kondisi }\end{array}$ & $\begin{array}{l}\text { a. Tujuan umum dan } \\
\text { khusus dalam suatu } \\
\text { metode } \\
\text { b. Model silabus } \\
\text { - Kriteria untuk } \\
\text { seleksi dan } \\
\text { organisasi linguistik } \\
\text { dan atau pokok } \\
\text { bahasan } \\
\text { c. Tipe-tipe aktivitas } \\
\text { pembelajaran dan } \\
\text { pengajaran } \\
\text { - Jenis-jenis tugas dan } \\
\text { aktivitas. } \\
\text { - Taraf kontrol yang } \\
\text { dimiliki pembelajar } \\
\text { terhadap isi }\end{array}$ & $\begin{array}{l}\text { a. Teknik, praktik dan } \\
\text { perilaku yang diamati } \\
\text { ketika metode itu } \\
\text { digunakan } \\
\text { - Sumber-sumber } \\
\text { yang berkaitan } \\
\text { dengan waktu, } \\
\text { ruang dan } \\
\text { perlengkapan yang } \\
\text { digunakan oleh } \\
\text { guru. } \\
\text { - Pola-pola interaksi } \\
\text { yang diamati dalam } \\
\text { pembelajaran. } \\
\text { - Taktik yang } \\
\text { digunakan guru dan } \\
\text { pembelajar ketika }\end{array}$ \\
\hline
\end{tabular}




\begin{tabular}{|l|l|l|}
\hline yang & pembelajaran. & metode itu \\
memungkinkan & - Pola-pola kelompok & digunakan. \\
keberhasilan & belajar yang \\
penggunaan proses- & diajukan atau \\
proses tersebut. & diimplementasikan. \\
& - Taraf pengaruh antar \\
& pembelajar. \\
& - Pandangan \\
& pembelajar sebagai \\
& pemroses, penyusun, \\
& penginisiatif dan \\
& pemecah masalah. \\
\hline
\end{tabular}

Berdasarkan formula baru mereka, Richards dan Rogers membuat dua prinsip yang berkontribusi pada pengertian tentang konsep sebuah metode. Konsep metode Richards terskema dengan enam faktor penting dari desain; tujuan, silabus, kegiatan, peran pembelajar, peran pengajar, dan peran bahan ajar.

Seluruh konsep metode yang terpisah tidak lebih lama menjadi isu sentral dalam pembelajaran bahasa secara praktis. Sebagai gantinya kita saat ini membuat referensi yang cukup mengenai metodologi sebagai payung pemahaman, pemesanan jangka panjang sebuah metode untuk sesuatu yang lebih khusus, teridentifikasi secara berkelompok dari teori yang cocok sebagai teknik dalam kelas.

Dalam bukunya Approaches and Methods in Language Teaching, Richards menyuguhkan beberapa metode pembelajaran bahasa sesuai dengan konsep yang telah diuraikan di atas. Adapun beberapa metode yang disebutkan di sana adalah, Oral Approach dan Situasional Language Teaching, audiolingual method, total physical response, the silent way, community language learning, sugestopedia (Abidin, 2006: 47), whole language (Rafli \& Lustyantie, 2016: 238), multiple intelegances, neurolinguistic programming, the lexical approcah, competency based language 
teaching, communicative language teaching, the natural approach, cooperative language learning, content-based instruction, task based language teaching, the post methods-era (Solikhah, 2014: 152.) Namun khusus pada keterampilan berbahasa reseptif, ada tiga metode yang kemudian akan diuraikan, untuk lebih mudahnya silahkan perhatikan tebel berikut;

\begin{tabular}{|c|c|c|c|}
\hline Metode & Pendekatan (approach) & Design & Prosedur \\
\hline $\begin{array}{l}\text { Oral Approach } \\
\text { dan Situasional } \\
\text { Language } \\
\text { Teaching }\end{array}$ & $\begin{array}{l}\text { Teori } \\
\text { "Structuralisme" } \\
\text { Pidato dianggap sebagai } \\
\text { dasar bahasa dan } \\
\text { struktur dipandang } \\
\text { berada di ambang } \\
\text { kemampuan berbicara. } \\
\text { Teori Pembelajaran } \\
\text { behaviorist habits- } \\
\text { learning }\end{array}$ & 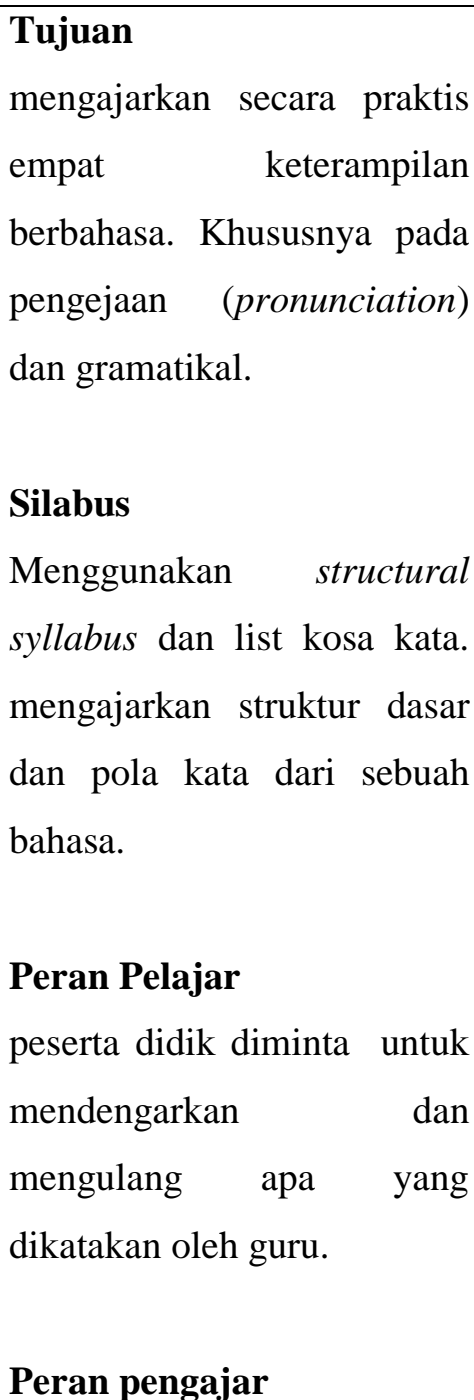 & $\begin{array}{l}\text { Model ini } \\
\text { dilakukan } \\
\text { berdasarkan } \\
\text { tingkatan. } \\
\text { Namun, } \\
\text { prosedur pada } \\
\text { level apapun } \\
\text { perlu dikontrol } \\
\text { untuk } \\
\text { membebaskan } \\
\text { praktik strutr } \\
\text { dari oral. }\end{array}$ \\
\hline
\end{tabular}




\begin{tabular}{|c|c|c|c|}
\hline & & $\begin{array}{l}\text { Pengajar harus membuat } \\
\text { model pembelajaran, } \\
\text { menyetting situasi yang } \\
\text { dibutuhkan sesuai dengan } \\
\text { target struktur dan kosa kata, } \\
\text { kemudian melakukan } \\
\text { permodelan. }\end{array}$ & \\
\hline $\begin{array}{l}\text { Audiolingual } \\
\text { Method }\end{array}$ & $\begin{array}{l}\text { Teori } \\
\text { structural linguistics } \\
\text { Teori pembelajaran } \\
\text { Behavioral Psycology } \\
\text { (stimulus, respon, dan } \\
\text { reinforcement) }\end{array}$ & 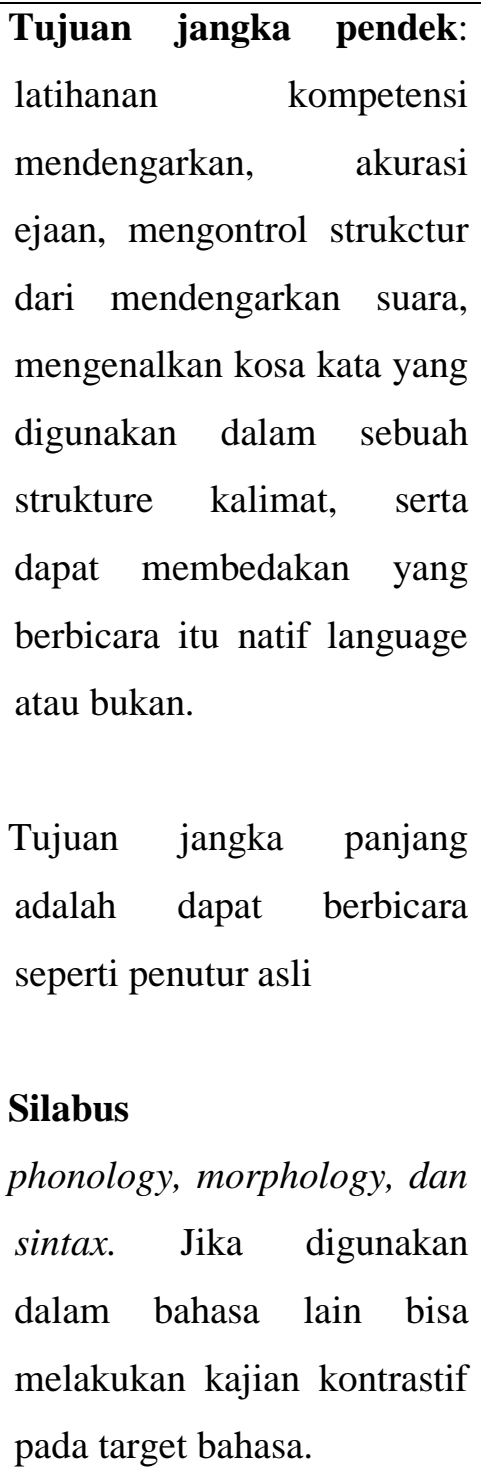 & $\begin{array}{l}\text { Prosedur } \\
\text { pengajaran } \\
\text { bahasa } \\
\text { melibatkan } \\
\text { aktifitas oral. } \\
\text { fokus pada } \\
\text { akurasi } \\
\text { berbicara } \\
\text { medium } \\
\text { instruksi, } \\
\text { mengunaan } \\
\text { terjemahan, } \\
\text { kecil dan besar } \\
\text { kelas bisa. }\end{array}$ \\
\hline
\end{tabular}




\begin{tabular}{|c|c|c|c|}
\hline & & $\begin{array}{l}\text { Teaching Activitas } \\
\text { dialog dan latihan } \\
\text { Peran pelajar } \\
\text { pelajar berperan sebagai } \\
\text { objek yang secara langsung } \\
\text { agar dapat memberikan } \\
\text { respon yang tepat. } \\
\text { Guru } \\
\text { memliki peran sentral, dan } \\
\text { mendominasi } \\
\text { Model intruksi materi } \\
\text { materi mendampingi guru } \\
\text { untuk membangun } \\
\text { penguasaan bahasa pada } \\
\text { pelajar. } \\
\text { menggunakan texk book }\end{array}$ & \\
\hline The Silent Way & $\begin{array}{l}\text { Teori } \\
\text { Strucktural approach } \\
\text { pelajar harus bisa } \\
\text { mendapatkan feel dari } \\
\text { bahasa target yang } \\
\text { dipelajari }\end{array}$ & $\begin{array}{lr}\text { mengajarkan } & \text { pembelajar } \\
\text { bagaimana cara } & \text { belajar } \\
\text { bahasa, dan keterampilan- } & \text { yang } \\
\text { keterampilan } & \text { melalui } \\
\text { dikembangkan bahasa } \\
\text { proses pembelajaran baha } \\
\text { asing atau bahasa kedua } \\
\text { dapat digunakan untuk }\end{array}$ & $\begin{array}{l}\text { mengunakan } \\
\text { format standar } \\
\text { pronuncation }\end{array}$ \\
\hline
\end{tabular}




\begin{tabular}{|l|l|l|}
\hline & $\begin{array}{l}\text { mempelajari segala hal lain } \\
\text { yang belum diketahui. }\end{array}$ \\
\hline
\end{tabular}

\section{Pengaruh dan Kritik Pemikiran Richards}

Richards dalam bukunya telah berhasil membuat sistem dalam metode pengajaran bahasa dengan sangat rigit. Mulai dari metode, pendekatan, desain, dan prosedur pelaksanaan yang diuraikan secara teknis. Bagi pengajar bahasa, tentu gagasan dari Richars tersebut bisa menjadi jalan pintas dalam membuat rancangan pembelajaran bahasa asing. Tidakk heran, jika buku tersebut masih dibutuhkan oleh publik dan memiliki pengaruh luas.

Metode yang dimuat dalam bukunya Richards tersebut bukanlah model baru, beberapa sudah pernah diterapkan pada pembelajaran bahasa asing di Eropa ataupun di Amerika Serikat. Upaya trobosan yang dilakukan dengan meletakkan metode itu pada konsep yang dibangunnya dalam pembelajaran bahasa.

Penjelasan dari Richards terkait dengan metode yang begitu terskema dengan detail menjadikan metode tersebut tidak lues. Dampak negatifnya tentu pada para pengajar yang terlalu terpaku pada gagasan Richards, sehingga terjerembab pada satu titik dan akan mengalami kesulitan untuk melakukan inovasi-inovasi baru. Sebab bagaimanapun, dalam pembelajaran sebuah bahasa tidak ada metode tunggal karena setiap metode mengajar memliki kelebihan dan kelemahan. metode-metode tersebut dapat digunakan dalam tujuan tertentu dan situasi tertentu (Rafli \& Lustyantie, 2016: 237).

Selajutnya jika diamati mendalam dari gagasan Richards, metode pembelajaran bahasa yang dikembangkannya berorentasi pada struktural. Seolah-olah kemampuan kemampuan berbahasa hanya fokus pada penguasaan aturan-aturan kebahasaan (competence) dan bagaimana menggunakannya (performance). Pandangan ini berimplikasi pada pembelajaran bahasa yang menekankan pada penguasaan gramatika meliputi struktur kata, struktur kalimat, kosa kata, makna kata/kalimat, ejaan, dan lafal lebih dulu sebelum pembelajar menguasai kemampuan komunikasi (strukturalis). Ini 
semakin terlihat jelas bisa diperhatikan pada pendekatan dari metode yang dikembangkan Richards dalam bukunya.

\section{Persamaan dan Perbedaan Pemikiran Ibrahim Abdul Alim dan Richards}

Ibrahim dan Richards memiliki persamaan yang mendasar dalam mengembangkan metode pengajaran bahasa, yaitu melibatkan pendekatan keilmuan psikologi, khususnya pada behaviorisme (prilaku peserta didik). Mereka bedua juga memeparkan bagaimana metode pengajarannya dengan sangat jelas mencakup prosedur, sesuai dengan tujuan yang diharapkan dalam pembelajaran tersebut.

Sementara itu, tidak dipungkuri keduanya memiliki perbedaan yang sangat signifikan. Ibrahim secara explisit menyebutkan, istima $\bar{a}$ ' menjadi bagi bagian dari jenis keterampilan membaca, di antara al-qirā'ah ashāmitah (membaca diam) dan qirā'ah jahariyah (membaca terang), sedangkan Richards tidak melakukan pengkategorian tersebut. Selain itu, orientasi dari keterampilan pembelajaran mereka berdua juga berbeda, Ibrahim lebih pada esensi pesan yang ingin disampaikan, pemahaman pada struktur kalimat agar bisa menyampaikan pesan dengan baik, sehingga pendekatan yang dilakukan lebih fungsionalis, sedangkan Richards lebih pada pendekatan strukturalis, ia mendasarkan keterampilan berbahasa agar bisa memahami struktur dan menyampaikan dengan ketepatan oral. 


\section{PENUTUP}

\section{Kesimpulan}

Dari beberapa ulasan di atas, dapat di simpulkan beberapa hal penting yang menjadi poin utama dalam paper ini.

Dalam pembelajaran bahasa reseptif (تعلم اللغة الاستقبالية) yang berkaitan dengan keterampilan mendengarkan dan membaca harus memiliki pola yang jelas, mulai dari pendekatan yang digunakan, desain pembelajaran termasuk juga tujuan dari pendekatan tersebut, yang bagaimana prosedur pelaksanaan. Seperti yang dilakukan Richards, ini merevisi gagasan dari Anthony kemudian menjadikan metode sebagai paying utama dalam pembelajaran Bahasa kemudian baru diikuti oleh pendekatan, design, dan teknik pelaksanaan. Demikian juga dengan Ibrahim Abdul Alim yang memaparkan metodenya sesuai dengan tingkatan kemampuan dan pengetahuan siswa, namun tidak secara explisit mengikuti alur Richards, tapi dia juga menjelaskan tujuan dan teknik pengajaran di kelas.

\section{Rekomendasi}

Gagasan dua tokoh yang diulas pada paper ini, perlu dijadikan pedoman penting bagi praktisi pendidik bahasa di lembaga pendidikan formal atau non formal. Tujuannya tentu agar memiliki capaian jelas dan terukur serta cara mencapai tujuan tersebut. Namun, pada kesempatan ini, penulis masih belum bisa mengulas secara detail terkait dengan pemikiran Ibrahim Abdul Alim dan Richards lebih mendalam lagi. 


\section{DAFTAR PUSATAKA}

Abidin, Yunus, 2006, Perspektif dan Prinsip-Prinsip Pembelajaran Bahasa, Tasikmalaya: HZAA Press, 2006.

About Professor Richards, https://www.professorjackrichards.com/about/, diakses pada 29 November 2018.

Adawiyah, Rabiyatul, 2016, Peran Pembelajaran Keterampilan Berbahasa Reseptif dalam UpayaPeningkatan Keterampilan Berbahasa Produktif, Volume 10. No. 1 Januari 2016, (29-32)

Al- Quran Surat As-sadjah, ayat 9.

Al-Quran Terjemahan Kementerian Agama edisi revisi 2016.

Edward M. Anthony, Approach, Method, and Technique, ELT Journal, Volume XVII, Issue 2, 1 January 1963, https://doi.org/10.1093/elt/XVII.2.63 diakses pada 30 November 2018. Pages 63-67,

Juan de Dios Martínez Agudo, 2018, Emotions in Second Language Teaching (editor). Switzerland: Springer, hal. 445-449.

Mulyati, Yeti, 2014, Hakekat Keterampilan Berbahasa, Jakarta: PDF Ut.ac.id hal. 1.2

Rafli, Zainal dan Ninuk Lustyantie, 2016, Teori Pembelajaran Bahasa, Editor. Yogyakarta: Penerbit Garudhawaca, 2016 Cet II.

RELC Journal, $\underline{\text { https://journals.sagepub.com/doi/abs/10.1177/0033688218785195 }}$ diakses pada 30 November 2018.

Richards, Jack C. 2018, The Cambridge Guide to Learning English as a Second Language (editor), Cambridge: Cambridge University Press, 2018.

Richards, Jack C. dan Theodore S. Rodgers, 2001, Approach and Methods in Language Teaching, New York: Cambridge University Press, 2001. 
Richards, Jack C., 2006, Communicative Language Teaching Today, New York: Cambridge University Press, 2006, Hal. 43.

Richards, Jack. C. 2018, Planning a Language Course: Principles and Procedures, Singapore: Regional Language Centre and MarketAsia, 2018.

Richards, Jack. C. 2018, Product and process in second language teacher education, Shanghai: Shanghai Foreign Language Education Press, 2018.

Solikhah, Imroatus 2014, Paradigam Baru Pembelajaran Bahasa dan Resistensi Masyarakat terhadap Perubahan, Cendekia, Vol. 8, No. 2 Oktober 151-168

Tarigan, Henry Guntur, 2009, Strategi Pengajaran dan Pembelajaran Bahasa,

http://www.bookssd.com/2012/11/blog-post_14.html, diakses الاملاء والترقيم فن كتابة العربية pada 3 Desember 2018.

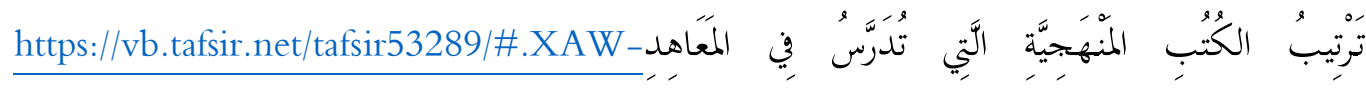

UTOIbIU, diakses pada 3 Desember 2018

عبد العليم إبراهيم، الموجه الفني لملدري اللغة العربية، القاهرة: دار المعارف، الطبعة الرابعة العشرة

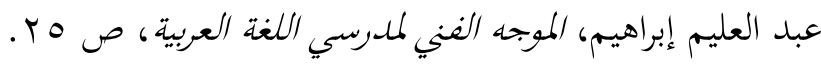

